\title{
Considerations for Insulin-Treated Type 2 Diabetes Patients During Hospitalization: A Narrative Review of What We Need to Know in the Age of Second- Generation Basal Insulin Analogs
}

\author{
Sherwin C. D'Souza (D) · Davida F. Kruger
}

Received: June 24, 2020 / Published online: September 30, 2020

(C) The Author(s) 2020

\begin{abstract}
With the availability of second-generation basal insulin analogs, insulin degludec (100 and 200 units/ml [degludec]) and insulin glargine 300 units/ml (glargine U300), clinicians now have long-acting, efficacious treatment options with stable pharmacokinetic profiles and associated low risks of hypoglycemia that may be desirable for many patients with type 2 diabetes. In this narrative review, we summarize the current evidence on glycemic control in hospitalized patients and review the pharmacokinetic properties of degludec and glargine U300 in relation to the challenges these may pose during the hospitalization of patients with type 2 diabetes who are receiving outpatient regimens involving these newer insulins. Their increased use in clinical practice requires that hospital healthcare professionals (HCPs) have appropriate protocols to transfer patients from these second-generation insulins to formulary
\end{abstract}

Digital Features To view digital features for this article go to https://doi.org/10.6084/m9.figshare.12861062.

S. C. D'Souza ( $\square)$

St Luke's Regional Medical Center, Boise, ID, USA

e-mail: dsouzas@slhs.org

D. F. Kruger

Henry Ford Hospital, Detroit, MI, USA insulin on admission, and ensure the safe discharge of patients and transition back to degludec or glargine U300. However, there is no guidance available on this. Based on the authors' clinical experience, we identify key issues to consider when arranging hospital care of such patients. We also summarize the limited available evidence on the potential utility of these second-generation basal insulin analogs in the non-critical inpatient setting and identify avenues for future research. To address current knowledge gaps, it is important that HCPs are educated about the differences between standard formulary insulins and second-generation insulins, and the importance of clear communication during patient transitions.

Keywords: Clinical guidance; Glycemic control; Hospital setting; Hyperglycemia; Hypoglycemia; Insulin degludec; Insulin glargine U300; Transition of care 


\section{Key Summary Points}

The past decade has seen many advances in diabetic therapies and devices including the development and availability of second-generation basal insulin analogs, which have properties that facilitate glycemic management in the context of everyday living.

The uptake of these second-generation basal insulin analogs in clinical practice requires that hospital healthcare professionals (HCPs) have appropriate protocols to safely transfer patients from these second-generation insulins to formulary insulin on admission, and ensure the safe discharge of patients and transition back.

To address current knowledge gaps and the limited guidance, it is important that hospital HCPs are educated about the differences between standard formulary insulins and second-generation insulins, and the importance of clear communication during patient transitions.

\section{DIGITAL FEATURES}

This article is published with digital features to facilitate understanding of the article. You can access the digital features on the articles associated Figshare page. To view digital features for this article go to https://doi.org/10.6084/m9. figshare.12861062.

\section{INTRODUCTION}

The past decade has seen many advances in diabetic therapies and devices, allowing healthcare professionals (HCPs) to better tailor treatment strategies to patient needs $[1,2]$. As the use of these recently available therapies in clinical practice increases, and as the prevalence of type 2 diabetes (T2D) continues to rise [3], it is likely that more patients will be admitted to the hospital on these newer therapies. At present, however, the guidance on diabetes care for hospitalized patients does not take this into account [4].

Among the newer treatment choices available are the second-generation basal insulin analogs, namely insulin degludec 100 units $/ \mathrm{ml}$ and 200 units/ml formulations (degludec U100 and U200, respectively [bioequivalent formulations]) [5] and insulin glargine 300 units $/ \mathrm{ml}$ (glargine U300) [6]. These insulins have lower variation in glucose-lowering effect (across $24 \mathrm{~h}$ and from day to day) $[7,8]$ and a reduced risk of hypoglycemia at a given level of $\mathrm{HbA}_{1 \mathrm{c}}$ compared with previously available products [9-11]. An extended duration of action with low peak:trough ratios at steady state also enables some flexibility in dose timing, and these properties all facilitate glycemic management in the context of everyday living [12]. A few studies investigating the use of degludec and glargine U300 in hospitalized patients have recently published findings, but the evidence is limited and the nuances of insulin management for inpatient scenarios where degludec and glargine U300 are involved have not been fully explored. Therefore, it is timely to take stock of what is known about managing T2D in hospitalized patients, and it is essential to educate HCPs about the differences between the standard formulary insulins and second-generation insulins.

In this narrative review, we aim to summarize current evidence on glycemic control in hospitalized patients with T2D and review the pharmacokinetic (PK)/pharmacodynamic (PD) properties of degludec U100 or U200 (hereafter referred to as degludec) and glargine U300 in relation to the challenges they may pose during hospitalization of patients with T2D on outpatient regimens involving these insulins.

\section{DIABETES CARE IN THE HOSPITAL}

Hospitalization presents unique challenges to glycemic control, including variation in 
nutritional status, mobility, and presence of acute illness. A number of physiological changes (e.g., stress-induced counter-regulatory hormone secretion) or therapeutic choices (e.g., glucocorticoid use) can result from acute illness and exacerbate hyperglycemia, which, in turn, can worsen acute illness [13]. The factors associated with hyperglycemia and hypoglycemia in insulin-treated hospitalized patients with diabetes are summarized in Table 1 ; the impact of these must be considered when managing care. Diabetes is rarely the primary focus of care in hospitalized patients, and it can be difficult to achieve glycemic control, but the increased cost, length of stay, and adverse outcomesincluding death-that are associated with both uncontrolled hyper- and hypoglycemia demonstrate how important it is $[14,15]$. There is great debate, however, on the optimal blood glucose (BG) target for hospitalized patients.

Table 1 Factors that influence BG control in insulin-treated hospitalized patients with diabetes

Factors that increase the risk of hyperglycemia $[59,60]$

Factors that increase the risk of hypoglycemia [59-62]

Patient characteristics

High insulin resistance

Advanced age

Previous poor glycemic control

Chronic kidney disease

Congestive heart failure

Duration of diabetes or insulin therapy

Food malabsorption (e.g., gastroenteritis or celiac disease)

Liver disease

Malignancies

Malnutrition

Prior episode(s) of hypoglycemia

Renal failure

Type 1 diabetes

Clinical status and therapeutic choices

Critical illness

Decreased activity levels/persistent bed rest

Enteral or parenteral nutrition

Increased appetite/recent end of nil per os status

Release of stress hormones

Sudden initiation, or dose increase, of concomitant corticosteroids

Diabetes management

Excessive insulin dose adjustment at admission

Failure to adjust insulin dosing with changing clinical status

Inadequate or no BG monitoring

Insulin dispensing error

Interruption to BG monitoring routine (e.g., transportation off the ward)

Overfeeding/'outside' carbohydrate-rich food brought into hospital for the patient
General anesthetic or sedation

Infection

New nil per os status

Reduced or unpredictable appetite

Renal failure

Sepsis

Shock

Sudden termination, or dose reduction, of corticosteroid therapy

Trauma

Failure to adjust insulin dosing with changing clinical status

Inadequate insulin dose adjustment at admission

Inadequate or no BG monitoring

Insulin dispensing error

Interruption to $\mathrm{BG}$ monitoring routine (e.g., transportation off the ward)

Mismatch between nutritional insulin administration and food delivery

Factors identified from the previously published literature and the authors' clinical experience BG, blood glucose 


\section{Glycemic Control in Critically Ill Hospitalized Patients with Diabetes}

In 2009, the American Diabetes Association (ADA) and the American Association of Clinical Endocrinologists issued joint guidance recommending a BG target range of $140-180 \mathrm{mg} /$ dl $(7.8-10.0 \mathrm{mmol} / \mathrm{l})$ in the majority of critically ill patients, in addition to pre-meal $(<140 \mathrm{mg} / \mathrm{dl} \quad[7.8 \mathrm{mmol} / \mathrm{l}])$ and spontaneous $(<180 \mathrm{mg} / \mathrm{dl}[10.0 \mathrm{mmol} / \mathrm{l}])$ targets in most non-critically ill patients, provided these targets can be safely achieved [15]. Evidence since has shown that clinical outcomes may be modified by preadmission glycemic control in hospitalized patients [16, 17]. In one retrospective observational study, relaxed BG targets were associated with lower mortality in critically ill patients with poorly controlled diabetes $\left(\mathrm{HbA}_{1 \mathrm{c}}>7 \%[53 \mathrm{mmol} / \mathrm{mol}]\right)$, but not in patients with well-controlled diabetes $\left(\mathrm{HbA}_{1 \mathrm{c}} \leq 7 \%\right.$ [53 mmol/mol]) [16]. This led Marik and Egi to propose differential therapeutic BG targets in intensive care unit patients with diabetes based on preadmission glycemic control: $140-200 \mathrm{mg} / \mathrm{dl}$ (7.8-11.1 mmol/l) in patients with preadmission $\mathrm{HbA}_{1 \mathrm{c}}<7 \%$ (53 mmol/mol) and 160-220 mg/dl $(8.9-12.2 \mathrm{mmol} / \mathrm{l})$ in those with preadmission $\mathrm{HbA}_{1 \mathrm{c}} \geq 7 \%$ (53 mmol/mol) [18].

\section{Glycemic Control in Patients with Diabetes Hospitalized for Surgical Procedures}

The optimal glycemic target during the perioperative period is still controversial [19]. In a recent meta-analysis, perioperative 'tight' $(\leq 150 \mathrm{mg} / \mathrm{dl} \quad[8.3 \mathrm{mmol} / \mathrm{l}])$ versus 'liberal' $(\leq 220 \mathrm{mg} / \mathrm{dl}[12.2 \mathrm{mmol} / \mathrm{l}])$ control was associated with reduced rates of some complications (surgical-site infections, sepsis, atrial fibrillation, and acute kidney injury [21-43\% lower]), but there was no survival benefit, and an increased risk of hypoglycemia (114\% higher) and severe hypoglycemia (382\% higher) [19]. The 2020 ADA standards of care do not recommend glycemic targets that are any tighter than $80-180 \mathrm{mg} / \mathrm{dl} \quad(4.4-10.0 \mathrm{mmol} / \mathrm{l})$ during the perioperative period, since this is associated with a higher incidence of hypoglycemia [14].

\section{Hypoglycemia in Hospitalized Patients with Diabetes}

Hypoglycemia is relatively common in hospitalized patients, with prevalence ranging from 3 to $28 \%$ (depending on the definition and setting) in patients with T2D [20-22]. In hospitalized patients with diabetes, hypoglycemia is associated with increased costs, mainly through longer hospital stays, alongside higher rates of morbidity and mortality [23, 24]. In critically ill patients, hypoglycemia is independently associated with increased risk of mortality [25] and, in non-critically ill patients (T2D: 99.4\%) admitted to hospital for infections, mortality risk was increased by hypoglycemia (2.66 times more likely than in patients without hypoglycemia) [26]. In combination with previous findings $[27,28]$, this provides a strong evidence base for the goal of avoiding hypoglycemia [25].

In conclusion, it appears that, while the optimal glucose target may vary between patients (with more research on this required), the best outcomes are achieved when hypoglycemia is avoided and BG variability minimized. It might be appropriate (or at least pragmatic) to relax glucose targets slightly during hospitalization, but nevertheless aim for the best level of control that can be achieved without incurring episodes of hypoglycemia.

\section{Anti-Hyperglycemic Agents in Hospitalized Patients}

Insulin is the most appropriate agent for controlling glycemia in hospitalized patients because it has no absolute contraindications, it is the most efficacious pharmacologic agent for lowering blood glucose, and it can be rapidly titrated. Oral antidiabetic drugs are generally discontinued upon admittance to hospital, since fewer data are available on their safety in hospitalized patients and it is not easy to adjust their dose based on the clinical status of the patient. In the critical care setting, continuous intravenous insulin infusion is the preferred 
method for achieving glycemic targets, as it allows quick correction for any sudden changes in insulin requirements. For non-critical care, choosing the most appropriate insulin regimen is not as clear and the choice depends on the individual circumstances, including whether patients have good nutritional intake, but a basal-bolus regimen is often the preferred regimen of choice for non-critically ill hospitalized patients $[14,29]$.

\section{SECOND-GENERATION BASAL INSULIN ANALOGS}

This section focuses on PK/PD properties and associated clinical outcomes of degludec and glargine U300 in clinical practice and the impact of their availability on insulin management of hospitalized patients with T2D.

\section{Insulin Degludec}

Degludec is a second-generation basal insulin that forms a depot of multi-hexamer chains after subcutaneous injection [30]. Gradual diffusion of readily absorbed degludec monomers from this depot provides a slow delivery of degludec into the circulation [30]. Table 2 provides an overview of its PK/PD properties. Degludec has an ultra-long duration of action (beyond $42 \mathrm{~h}$ ) and an elimination half-life of $\sim 25 \mathrm{~h}$ [31]; clinicians may be concerned that this results in an excessive accumulation of insulin in the circulation (insulin stacking) with once-daily dosing. However, basal insulin only accumulates until steady state is reached, at which time the daily injected dose is balanced by elimination [32]. Degludec has a stable and consistent glucose-lowering profile over the daily dosing interval with little peak effect $[8,31]$. These properties of degludec are preserved across pediatric and elderly patients, and those with renal or hepatic impairment [33-36].

Randomized controlled trials (RCTs) have demonstrated comparable glycemic control and a lower risk of hypoglycemia with degludec compared with glargine U100 in patients with diabetes [10, 11, 37]. The long-term safety of degludec has been established in DEVOTE, a dedicated cardiovascular outcomes trial [37]. Degludec is also available in an up-concentrated formulation, insulin degludec 200 units $/ \mathrm{ml}$ (degludec U200), which is bioequivalent to degludec U100 [38] and may help to address the needs of patients with a high injection volume burden.

\section{Insulin Glargine U300}

Glargine U300 contains the same active molecule as the first-generation basal insulin analog glargine U100 but is an up-concentrated formulation delivering the same number of insulin units in one-third of the injection volume [6]. After subcutaneous injection, the acidic glargine solution is neutralized and the glargine component precipitates, forming an amorphous depot, slowing its absorption from subcutaneous tissue [6]. Upon redissolution, glargine is predominantly locally converted into a metabolite that is responsible for its glucose-lowering effect [39]. There are differences in the PK/PD profiles between the two glargine formulations (U100 and U300) [7], and these are thought to result from differences in injection volume and, therefore, depot size, leading to slower and more prolonged redissolution from a more compact glargine U300 depot [40]. Glargine U300 has a long duration of action ( $\geq 36 \mathrm{~h})$, an elimination half-life of 18-19 h (Table 2) [6, 7], and a more stable glucose-lowering profile than glargine U100 [7].

In the EDITION trials program, patients with diabetes achieved equivalent glycemic control with glargine U300, but at a higher insulin dose (10-18\%) compared with glargine U100 [6, 9]. There were comparable or lower risks of experiencing at least one confirmed $(B G \leq 70 \mathrm{mg} / \mathrm{dl}$ [3.9 $\mathrm{mmol} / \mathrm{l}]$ ) or severe episode of hypoglycemia at any time (24-h period) or during the night with glargine U300 versus glargine U100 [9]. However, lower rates of hypoglycemia with glargine U300 in the EDITION program appear to be largely driven by data from the titration period (week 0 -week 8 ) and might be attributed to differences in potency between the U100 and 
Table 2 PK/PD properties and relevant practical aspects of basal insulin products

\begin{tabular}{|c|c|c|c|c|c|}
\hline & \multicolumn{2}{|c|}{ Second-generation basal insulin analogs } & \multicolumn{2}{|c|}{ First-generation basal insulin analogs } & \multirow{2}{*}{$\begin{array}{l}\text { Intermediate- } \\
\text { acting basal } \\
\text { insulin } \\
\mathrm{NPH} \text { insulin }{ }^{\mathrm{a}} \\
{[70-72]}\end{array}$} \\
\hline & Degludec $[5,63]$ & $\begin{array}{l}\text { Glargine U300 } \\
{[6,64]}\end{array}$ & Detemir $[65-68]$ & $\begin{array}{l}\text { Glargine } \mathrm{U} 100 \\
{[64,65,69]}\end{array}$ & \\
\hline Onset of action & $1 \mathrm{~h}$ & $\leq 6 \mathrm{~h}$ & $1-2 \mathrm{~h}$ & $1-2 \mathrm{~h}$ & $2 \mathrm{~h}$ \\
\hline $\begin{array}{l}\text { Time to reach } \\
\text { steady state } \\
\text { (OD } \\
\text { administration) }\end{array}$ & $2-4$ days & $\leq 5$ days $^{\mathrm{b}}$ & $\begin{array}{l}\text { 2-3 doses with } \\
\text { BID dosing }\end{array}$ & $2-4$ days & $3-4$ doses $^{c}$ \\
\hline $\begin{array}{l}\text { Elimination half- } \\
\text { life at steady } \\
\text { state }\end{array}$ & $25 \mathrm{~h}$ & $15-19 \mathrm{~h}$ & $5-7 \mathrm{~h}$ & $13-14 \mathrm{~h}$ & $4 \mathrm{~h}$ \\
\hline $\begin{array}{l}\text { Duration of } \\
\text { action at steady } \\
\text { state }\end{array}$ & $>42 \mathrm{~h}$ & $\leq 36 \mathrm{~h}$ & $<24 \mathrm{~h}$ & $24 \mathrm{~h}$ & $12 \mathrm{~h}$ \\
\hline $\begin{array}{l}\text { Median time to } \\
\text { maximum } \\
\text { serum insulin } \\
\text { concentration }\end{array}$ & $9 \mathrm{~h}$ & $12-16 \mathrm{~h}$ & $6-8 \mathrm{~h}$ & $8-12 \mathrm{~h}$ & $4 h^{d}$ \\
\hline $\begin{array}{l}\text { Recommended } \\
\text { interval } \\
\text { between dose } \\
\text { adjustments }\end{array}$ & $3-4$ days & $3-4$ days & 3 days & & \\
\hline $\begin{array}{l}\text { Recommended } \\
\text { timing of } \\
\text { injections }\end{array}$ & Any time of day ${ }^{\mathrm{e}}$ & Same time of day ${ }^{\mathrm{f}}$ & $\begin{array}{l}\text { OD dosing: } \\
\text { evening; BID: } \\
\text { once morning } \\
\text { and once } \\
\text { evening }\end{array}$ & Same time of day & $\begin{array}{l}\text { 1-3 times } \\
\text { daily }\end{array}$ \\
\hline \multicolumn{6}{|c|}{ Use in special populations: } \\
\hline Pediatric & $\begin{array}{l}\text { Indicated in } \\
\text { patients } \geq 1 \text { year } \\
\text { old }\end{array}$ & $\begin{array}{l}\text { Indicated in } \\
\text { patients } \geq 6 \text { years } \\
\text { old }\end{array}$ & $\begin{array}{l}\text { Indicated in } \\
\text { patients } \\
2-17 \text { years old }\end{array}$ & $\begin{array}{l}\text { Indicated in } \\
\text { patients } \\
6-15 \text { years old } \\
\text { with type } 1 \\
\text { diabetes; not } \\
\text { studied for type } 2 \\
\text { diabetes }\end{array}$ & $\begin{array}{r}\text { Not been } \\
\text { studied }\end{array}$ \\
\hline Elderly & $\begin{array}{l}\text { Greater caution } \\
\text { should be } \\
\text { exercised }\end{array}$ & $\begin{array}{l}\text { Caution should be } \\
\text { exercised }\end{array}$ & $\begin{array}{l}\text { Greater sensitivity } \\
\text { cannot be ruled } \\
\text { out }\end{array}$ & $\begin{array}{l}\text { Caution should be } \\
\text { exercised }\end{array}$ & $\begin{array}{r}\text { Not been } \\
\text { studied }\end{array}$ \\
\hline
\end{tabular}


Table 2 continued

\begin{tabular}{|c|c|c|c|c|c|}
\hline & \multicolumn{2}{|c|}{ Second-generation basal insulin analogs } & \multicolumn{2}{|c|}{ First-generation basal insulin analogs } & \multirow{2}{*}{$\begin{array}{l}\text { Intermediate- } \\
\text { acting basal } \\
\text { insulin } \\
\text { NPH insulin } \\
{[70-72]}\end{array}$} \\
\hline & Degludec $[5,63]$ & $\begin{array}{l}\text { Glargine U300 } \\
{[6,64]}\end{array}$ & Detemir [65-68] & $\begin{array}{l}\text { Glargine U100 } \\
{[64,65,69]}\end{array}$ & \\
\hline $\begin{array}{l}\text { Renal } \\
\text { impairment }\end{array}$ & $\begin{array}{l}\text { No clinically } \\
\text { relevant PK } \\
\text { difference in } \\
\text { patients with } \\
\text { impairment } \\
\text { (versus those } \\
\text { without) }\end{array}$ & Not been studied & $\begin{array}{l}\text { No PK difference } \\
\text { in patients with } \\
\text { renal } \\
\text { impairment } \\
\text { (versus those } \\
\text { without) }\end{array}$ & Not been studied & $\begin{array}{r}\text { Not been } \\
\text { studied }\end{array}$ \\
\hline $\begin{array}{l}\text { Hepatic } \\
\text { impairment }\end{array}$ & $\begin{array}{l}\text { No PK difference in } \\
\text { patients with } \\
\text { hepatic } \\
\text { impairment } \\
\text { (versus those } \\
\text { without) }\end{array}$ & Not been studied & $\begin{array}{l}\text { Lower exposure in } \\
\text { patients with } \\
\text { severe hepatic } \\
\text { impairment } \\
\text { (versus those } \\
\text { without) }\end{array}$ & Not been studied & $\begin{array}{r}\text { Not been } \\
\text { studied }\end{array}$ \\
\hline
\end{tabular}

BID twice daily, detemir insulin detemir, glargine U100 insulin glargine 100 units $/ \mathrm{ml}$, glargine U300 insulin glargine 300 units/ml, NPH neutral protamine Hagedorn, $O D$ once daily, $P D$ pharmacodynamics, $P K$ pharmacokinetic

${ }^{\text {a }}$ If appropriately resuspended before subcutaneous injection

b The first dose may be insufficient to cover metabolic needs in the first $24 \mathrm{~h}$ of use

${ }^{c}$ Estimated based on the theoretical number of half-lives required for trough levels to reach $\geq 90 \%$ of the plateau concentration

${ }^{\mathrm{d}}$ Mean value reported

e With a minimum of $8 \mathrm{~h}$ and a maximum of $40 \mathrm{~h}$ between consecutive doses

$\mathrm{f} \pm 3 \mathrm{~h}[47]$

U300 formulations. The long-term safety of glargine U100 has been demonstrated in the ORIGIN cardiovascular outcomes trial [41], and that of glargine U300 is demonstrated in the CONCLUDE head-to-head trial [42].

\section{Head-to-Head Studies of Degludec and Glargine U300}

Studies have compared the PK profiles of the second-generation basal insulins and found that degludec achieves its (more or less) peakless profile from dose to dose more consistently than either glargine U100 or U300 formulations [8]. However, head-to-head trials investigating clinical outcomes have been inconsistent in their findings [43-45]. The latest data are from the CONCLUDE clinical trial. This randomized, open-label, treat-to-target trial compared the risk of hypoglycemia with degludec U200 versus glargine U300 over a 36-week maintenance period (total treatment period: 88-weeks) in 1609 insulin-treated patients with T2D [42]. Although the rate of overall symptomatic hypoglycemia (primary endpoint) was lower with degludec U200 compared with glargine U300 (216.8 versus 243.9 events per 100 patient-years of experience [PYE]), the difference did not reach statistical significance (RR $\left.0.88[0.73 ; 1.06]_{95 \% \mathrm{CI}}\right)$. As a result of the trial not meeting its primary endpoint, the confirmatory testing procedure for superiority was stopped and the prespecified confirmatory secondary hypoglycemia endpoints (nocturnal symptomatic hypoglycemia and severe 
hypoglycemia) were analyzed using prespecified statistical models but were now considered exploratory, since they could not be controlled for family-wise type I error. Nevertheless, these endpoints showed lower rates with degludec U200 versus glargine U300 for nocturnal symptomatic hypoglycemia $(62.3$ versus 93.8 events per 100 PYE, RR $\left.0.63[0.48 ; 0.84]_{95 \% \mathrm{CI}}\right)$ and severe hypoglycemia (1.0 versus 4.9 events per 100 PYE, RR: 0.20 [0.07; 0.57 $]_{95 \% ~ C I}$ ) [42].

To summarize, it remains to be established if one of the second-generation basal insulin analogs currently available has an advantage over the other for reducing risk of hypoglycemia at a given level of glycemic control [46], but they provide a much-needed treatment option for patients who require insulin therapy but are fearful of, or vulnerable to, hypoglycemia.

\section{Studies of Second-Generation Basal Insulin Analogs in Hospital Settings}

A lower risk of hypoglycemia and low variability in glucose-lowering effect are desirable properties to have in an insulin used to treat patients in the hospital setting, as well as in clinical practice; hence, several studies are investigating the utility of second-generation basal insulin analogs in hospitalized patients. The unique PK/PD profile of these newer insulins may be of benefit in certain hospital situations, but problematic in others. For example, day-to-day variability in glucoselowering effect can make it challenging to dose insulin correctly and safely, so the relatively low day-to-day variation demonstrated by degludec and glargine U300 may help address this issue. In addition, these insulins are appropriate for once-daily dosing and offer some dosing flexibility; degludec can be injected at any time of day, and flexibly from day to day as long as dosing is within an 8-40-h interval following the previous dose [5]. Glargine $\mathrm{U} 300$ can be injected $\pm 3 \mathrm{~h}$ of the same time each day without compromising glycemic control $[6,47]$. Such flexibility may be more practical and safe for hospitalized patients and those who rely on district or community nursing teams to administer insulin injections. The steady-state profiles of degludec and glargine U300 have a markedly lower peak:trough ratio than other insulin analogs with shorter half-lives. Consequently, fluctuations in glucose-lowering effect are dampened and insulin dosing errors, which are particularly prevalent in hospitals [48], have fewer acute effects [32].

However, their long half-lives (that afford these benefits) mean that they take longer to achieve steady state than first-generation basal insulins, and so titration should take place less frequently (label recommends every 3-4 days) than with other insulins to avoid overshooting the BG target $[5,6]$. This could make them unsuitable for use in hospitalized patients who may have fluctuating insulin requirements and unstable health status.

\section{Studies of Degludec in a Hospital Setting}

The majority of data available on degludec in the hospital setting are from small studies, but a large randomized trial comparing degludec with glargine U100, as part of a basal-bolus regimen, for the management of hospitalized and discharged patients with T2D is ongoing [49]. Findings from a small $(n=74)$, open-label, randomized, controlled trial conducted in Japanese hospitals have recently been published, albeit the patients were hospitalized for the specific purpose of initiating insulin; hence, the findings are not applicable to patients hospitalized as a result of acute illness/scheduled surgery. Nevertheless, this study provides insights into titrating degludec to target over a short period of time [50]. In this study, patients with poorly controlled $\left(\mathrm{HbA}_{1 \mathrm{c}} \geq 8 \%\right.$ [64 mmol/mol]) T2D were randomized to receive either degludec or glargine U100 as part of a basal-bolus regimen. Basal insulin was initiated at 4 units before bedtime, with dose adjustment every 2 days, and bolus insulin was started at 4 units before each meal. After 12 days, the percentage of patients achieving glycemic control was similar between groups $(\sim 30 \%)$, as was the proportion experiencing hypoglycemia [ $\sim 41 \%$, BG $\quad 54-70 \mathrm{mg} / \mathrm{dl} \quad(3.0-3.9 \mathrm{mmol} / \mathrm{l})$, $\sim 10 \% \quad \mathrm{BG}<54 \mathrm{mg} / \mathrm{dl} \quad(3.0 \mathrm{mmol} / \mathrm{l})]$. The 
glycemic targets and protocol used here are likely unsuitable for hospitalized patients, but it is reassuring that there was no increased risk of hypoglycemia with degludec versus glargine U100 [50]. Furthermore, a study in 12 patients who had a 24-h fasting period around their scheduled colonoscopy found patients could avoid hypoglycemia by skipping a single dose of degludec on the morning of the procedure [51].

There are few small observational studies on degludec use in acutely ill patients. One retrospective study assessed the impact of degludec on 13 patients with and 13 patients without T2D who were hospitalized and required parenteral/enteral nutrition [52]. The starting dose of degludec was calculated according to the carbohydrate content of the parenteral/enteral nutrition, usually applying a 1:10 ratio of insulin units:carbohydrate $(\mathrm{g})$. For patients coming from basal-bolus insulins, the dose of shortacting insulin had to be $50 \%$ of the total daily insulin dose at day 1, 25\% at day 2, and $12.5 \%$ at day 3 , while degludec reached steady state. In other patients, short-acting insulin was used when BG exceeded $250 \mathrm{mg} / \mathrm{dl}(13.9 \mathrm{mmol} / \mathrm{l})$. In the T2D patients, mean glucose intake was $181 \mathrm{~g}$ per day, mean degludec dose was 24-26 units per day, $46.1 \%$ of patients received short-acting insulin, and mean (SD) BG levels improved from $210(66.5) \mathrm{mg} / \mathrm{dl}$ [11.7 (3.7) $\mathrm{mmol} / \mathrm{l}$ to $192(48.6) \mathrm{mg} / \mathrm{dl}[10.7$ (2.7) $\mathrm{mmol} / \mathrm{l}]$ during the 7-day follow-up. No symptomatic or severe hypoglycemic episodes occurred during the hospital stay, and there was evidence of a reduction in within-day glycemic variability (as measured by the coefficient of variation of glycemia every $6 \mathrm{~h}$ ) [52]. Similar results were observed in an observational study of 52 noncritical patients with diabetes who received degludec as part of a basal-bolus regimen while hospitalized [53]. It is not possible to draw conclusions on the effect and safety of degludec-based regimens in hospitalized patients based on the current data available; it remains to be seen whether the outcomes described in these small observational studies will also be observed in large, randomized trials.

\section{Studies of Glargine U300 in a Hospital Setting}

The largest study with published findings so far is the glargine U300 hospital trial [54], in which 176 patients with poorly controlled T2D were randomized to receive a basal-bolus regimen with either glargine U300 or glargine U100 and insulin glulisine before meals after admission to hospital. Insulin-experienced patients received $80 \%$ of their total daily outpatient insulin dose, and starting dose for insulin-naïve patients was determined according to weight and glycemic control: 0.4 and 0.5 units $/ \mathrm{kg} /$ day for patients with BG levels of 140-200 and 201-400 mg/dl [7.8-11.1 and 11.2-22.2 $\mathrm{mmol} / \mathrm{l}]$, respectively. The total daily dose was split evenly between basal and prandial insulin, the latter divided in three equal doses before meals. The final titration protocol was to adjust basal and rapid-acting doses on a daily basis with increases of $10 \%$ [BG 140-180 mg/dl (7.8-10.0 mmol/l), 20\% (BG $180-240 \mathrm{mg} / \mathrm{dl}(10.0-13.3 \mathrm{mmol} / \mathrm{l})]$, and $30 \%$ [BG $>240 \mathrm{mg} / \mathrm{dl}(13.3 \mathrm{mmol} / \mathrm{l})]$ if patients were in poor glycemic control, but, during the first 6 months of study (before the first prespecified interim analysis), adjustments were only made if $\mathrm{BG}$ was $>180 \mathrm{mg} / \mathrm{dl} \quad(10.0 \mathrm{mmol} / \mathrm{l})$. Mean (SD) BG at admission was 228 (82) $\mathrm{mg} / \mathrm{dl}$ [12.7 (4.6) $\mathrm{mmol} / \mathrm{l}]$, and this improved in both treatment arms, with mean daily BG levels of 186 (40) $\mathrm{mg} / \mathrm{dl}[10.3(2.2) \mathrm{mmol} / \mathrm{l}]$ for the glargine U100 group and $184(46) \mathrm{mg} / \mathrm{dl}[10.2$ (2.6) mmol/l] with glargine U300. The median (interquartile range [IQR]) inpatient stay was 6 (4; 8) days with glargine U300 and $4(3 ; 7)$ days with glargine U100, and, overall, the level of glycemic control achieved was not impacted by duration of hospital stay. Capillary point-ofcare testing before meals and bedtimes revealed that the percentages of patients with $\mathrm{BG}<70 \mathrm{mg} / \mathrm{dl} \quad(3.9 \mathrm{mmol} / \mathrm{l})$ were similar between the glargine U100 group (8.7\%) and the glargine U300 group (9.5\%), but clinically significant hypoglycemia $\quad(B G<54 \mathrm{mg} / \mathrm{dl}$ [3.0 mmol/l]) occurred in $6 \%$ of glargine U100treated patients versus $0 \%$ of glargine U300treated patients $(p=0.02)$, and a single episode of severe hypoglycemia (BG $<40 \mathrm{mg} / \mathrm{dl}$ [2.2 mmol/l]) occurred with glargine U100. 
There were no significant differences in glycemic control in a subset of 82 patients using continuous glucose monitoring during their stay.

\section{Challenges of Interrupting Treatment with Second-generation Basal Insulin Analogs during Hospitalization}

Not all hospital formularies include secondgeneration basal insulins, so patients may need to be transferred to the available formulary basal insulin, and, in some cases, it might be more practical or desirable to transfer patients temporarily to continuous intravenous (IV) insulin infusion. The current lack of data and restricted formularies will mean that the vast majority of patients being treated with degludec or glargine U300 are likely to be switched to an insulin with a shorter half-life. Despite this, there are no guidelines on safely switching between second- and first-generation basal insulin analogs upon admittance and discharge from hospital [4]. While the prescribing information gives recommendations on how to switch to these newer insulins (unit-for-unit conversions except when switching from twicedaily basal insulin to glargine U300, where a $20 \%$ dose reduction is recommended) $[5,6]$, it is unknown whether these are suitable for patients who may have just undergone major changes in glucose handling before being discharged from hospital, and there is even less information on switching from these insulins. Table 3 presents a comparison of guidance (drawn from the authors' clinical experience) on the hospital care of patients with T2D receiving outpatient basal insulin regimens involving a first- or second-generation basal insulin analog.

In a recent paper, Hirsch and Draznin explored several clinical scenarios in which challenges may arise when switching from degludec to a basal insulin with a shorter halflife [4]. The authors surveyed 30 other HCPs on what they would do in each situation, and also offered their own recommendation, based on the PK/PD profile of the insulins involved. The most popular answer selected by HCPs often involved making unit-to-unit conversions between degludec and formulary insulins, but this may not be appropriate, especially in hospitalized patients who are vulnerable to hypoglycemia, because of the carry-over effect of previously injected degludec. For patients admitted to the hospital on degludec, the authors recommended halving their basal insulin dose on the first day they are switched to a first-generation formulary basal insulin and then upping the dose to $75-100 \%$ of the preadmittance insulin dose the next day (depending on BG levels) [4]. This is based on the knowledge that $50 \%$ of the last degludec dose is still contributing to the serum insulin levels $25 \mathrm{~h}$ post-injection, as indicated by the terminal half-life. This is a conservative approach to avoid hypoglycemia when switching from a second- to first-generation basal insulin in hospitalized patients. It is important to consider when exactly the patient's last dose was given, especially given the flexibility in degludec dosing. For example, if the last dose of insulin (degludec) was $>30 \mathrm{~h}$ ago, halving the next dose of insulin (e.g., glargine U100, onset of action $\leq 6 \mathrm{~h}$ ) may result in a temporary rise in glycemia. It is impossible to provide a precise and universal calculation for conversion, as every situation is different, and the factors listed in Table 1 will also determine patients' insulin requirements. Nevertheless, we would recommend considering a reduction in total daily insulin dose of between 20 and 50\% when switching non-critical patients from degludec to a first-generation basal insulin upon admittance to hospital and a similar magnitude in dose reduction when switching back to degludec upon discharge to reduce the risk of hypoglycemia.

While Hirsch and Draznin discussed the challenges pertaining to degludec, to the best of our knowledge, these same challenges have not been explored with explicit reference to glargine U300. For the most part, the same principles will apply; indeed, the glargine U300 hospital trial reduced insulin dose by $20 \%$ when switching from U100 to U300 formulations. However, given the relatively shorter half-life and lower unit dose potency of glargine U300 compared with degludec, somewhat smaller 
Table 3 Comparison of guidance (drawn from the authors' clinical experience) for the hospital care of patients with type 2 diabetes receiving outpatient basal insulin regimens

\begin{tabular}{ll}
\hline Guidance for outpatient regimens involving a second-generation basal insulin analog (degludec or glargine U300) \\
\hline Similarities to guidance for other outpatient basal insulin analogs $\mathrm{s}^{\mathrm{a}}$ & $\begin{array}{l}\text { Differences from clinical guidance for other outpatient basal insulin } \\
\text { analogs }^{\mathrm{a}}\end{array}$
\end{tabular}

Hospital admission

Assessment of outpatient glycemic control and review of hyper- and

hypoglycemia

Setting inpatient glycemic goals

Hospitalization

Choice of therapeutic regimen and the factors that influence this choice

Use of formulary insulin products, as required

Decision to discontinue other non-insulin glucose-lowering agents

Adjustment of insulin dose according to clinical status and to accommodate for changes in meals and activity levels, the effects of illness, and other medications (for degludec only)

Targeting a $\mathrm{BG}$ range

Scheduled POC BG testing (after $48 \mathrm{~h}$ )

At least a $20 \%$ reduction in total daily insulin dose when transferring a patient from second-generation basal insulin analogs to formulary insulin products $^{\mathrm{a}}$ to reduce the hypoglycemia risk

Extra scheduled POC BG tests at 00:00 and 03:00 for the first $48 \mathrm{~h}$

If the patient remains on the second-generation basal insulin analog in hospital, the basal insulin dose should be titrated no more frequently than every 3-4 days, with adjustments made to nutritional and/or supplemental insulin dosing as required and the patient should be closely followed up

Use of protocols to avoid and manage hypoglycemia

Evaluation of BG records (POC and laboratory test results) and

adjustment of nutritional and/or correctional insulin dose

Discharge from hospital

Written and verbal instructions on self-monitoring of BG, an explanation of home BG goals, and the importance of consistent nutritional habits

Caution that BG levels may be higher than normal for a few days after discharge

Transfer from formulary insulin products ${ }^{\mathbf{a}}$ to the previous basal insulin analog: convert the basal insulin dose on a unit-per-unit basis with glargine U300

Reintroduction and dosing of any non-insulin glucose lowering agents (if discontinued during hospitalization)

Therapeutic intensification or adjustment, if required

Emphasis that BG levels may be higher than normal for a few days after discharge, with verbal and written instructions advising that the basal insulin dose should be titrated no more frequently than every 3-4 days to avoid overshooting the BG target, putting the patient at risk of hypoglycemia

Consider at least a $20 \%$ dose reduction in the hospital formulary basal insulin ${ }^{\text {a }}$ dose to the degludec dose to be conservative

Provide verbal and written instructions to the patient that it may take up to 4 days to see the full effect of degludec or up to 5 days to see the full effect of glargine U300

Scheduling of follow-up visits

$B G$ blood glucose, glargine $U 300$ insulin glargine 300 units $/ \mathrm{ml}, P O C$ point of care

a First-generation basal insulin analogs (e.g., insulin glargine $100 \mathrm{units} / \mathrm{ml}$ or insulin detemir)

dose reductions may be appropriate when switching between glargine U300 and formulary insulin.

Another important point to consider when adjusting insulin during hospitalization is whether the patient's pre-admission insulin dose was appropriate. In cases where patient adherence is poor, the insulin dose can sometimes be inappropriately increased. Therefore, it may be best to also consider the insulin dose expected based on the patient's body weight and nutritional needs. This scenario is possibly less likely, however, in patients on degludec/ glargine U300 regimens, as the impact of missing a basal insulin dose becomes smaller as the half-life increases.

\section{Admitting a Patient on Newer Therapies to Hospital}

While there may not be enough evidence to draw conclusions on the utility of starting second-generation basal insulin analogs in hospitalized patients, the findings so far may help HCPs decide whether patients who are already being treated with a newer basal insulin should remain on that insulin during their hospital 
stay or be switched to an insulin with a shorter half-life. For example, the findings from the glargine U300 hospital trial do not indicate that a patient with T2D poorly controlled with glargine U300 would have better outcomes by being switched to glargine U100 upon admittance. This may mean that HCPs take the decision to keep patients on glargine U300 throughout, thereby avoiding the challenges and potential risks associated with switching between a first- and second-generation basal insulin. However, further study is required to support hospital HCPs in this decision and to ensure that future guidelines contain sufficient information on the challenges these new therapies pose to insulin management in an inpatient setting.

\section{Discharging a Patient from Hospital Formulary Insulin Back to Their Pre- Admission Regimen}

Irrespective of the inpatient diabetes treatment regimen, the transition of care from the inpatient to the outpatient setting represents a clinical challenge [55]. Discharge planning should commence at hospital admission and include steps to ensure appropriate communication across caregivers, reconciling medication across the continuum of care, arranging for timely follow-up, and encouraging active involvement from patients in their diabetes care [55]. Additional steps are advisable for patients switching back from the hospital formulary insulin to their pre-admission regimen involving a second-generation basal insulin analog (Table 3). For instance, patients should receive verbal and written instructions advising that the second-generation basal insulin dose should be titrated no more frequently than every 3-4 days to avoid overshooting the BG target, putting the patient at risk of hypoglycemia. A dose reduction should be considered in patients switching back to their home regimen involving degludec, while patients should be advised that it may take up to 4 days to see the full effect of degludec or up to 5 days to see the full effect of glargine U300 following discharge (Table 3).

\section{COVID-19 Infection in Patients with T2D}

Due to the recent emergence of COVID-19, there has not been an opportunity to study the relationship between T2D and susceptibility to COVID-19 infection in large cohorts; thus, a conclusive relationship is yet to be determined. However, retrospective studies of hospitalized patients with COVID-19 have demonstrated that, compared with non-diabetic patients, patients with $\mathrm{T} 2 \mathrm{D}$ require more intensive treatments in the management of COVID-19 symptoms, and have a significantly higher inhospital death rate [56]. Furthermore, wellcontrolled BG levels during COVID-19 infection are associated with better survival [56]. One retrospective study, although limited by patient numbers, indicated that patients with T2D who are critically ill with COVID-19 seem have a greater need for insulin at the peak of their COVID-19 infection [57]. The management of diabetes in patients with COVID-19 poses a clinical challenge that requires a balance between glucose-lowering treatments and treatments to manage the viral infection, in addition to careful consideration regarding the multiple factors that contribute to poor prognosis in patients with both COVID-19 and T2D [58]. The authors feel that it is too early to discuss the use of second-generation basal insulin analogs in COVID-19 patients.

\section{ETHICS APPROVAL}

This article is based on previously conducted studies and does not contain any studies with human participants or animals performed by any of the authors.

\section{CONCLUSIONS}

Optimal use of insulin in hospitalized patients with diabetes remains to be fully elucidated and continues to be a subject of ongoing study. The increased use of second-generation basal insulin analogs in clinical practice presents hospital HCPs with a challenge, since there is no guidance available on how to safely switch 
hospitalized patients from second- to first-generation basal insulin analogs. As more data become available on the possible utility of these newer insulins as part of a basal-bolus regimen in the hospital setting, hospital HCPs will be better able to decide whether non-critically ill patients can remain on their ultra-long-acting basal insulin. In any case, a carefully considered treatment plan for each individual patient is required, and this may require thought to be given to the initiation, continuation, adjustment, discontinuation, and recommencement of these insulins.

\section{ACKNOWLEDGEMENTS}

Funding. This review and the journal's Rapid Service Fee were funded by Novo Nordisk Inc.

Medical Writing, Editorial, and Other Assistance. Medical writing support was provided by Anna Campbell and technical editing support by Helen Marshall of Watermeadow Medical, an Ashfield company, part of UDG Healthcare plc, funded by Novo Nordisk Inc. The authors thank Michael Santiago (Novo Nordisk Inc.) for providing a medical accuracy review of the outline and final draft. This was funded by Novo Nordisk Inc.

Authorship. All named authors meet the International Committee of Medical Journal Editors (ICMJE) criteria for authorship for this article, take responsibility for the integrity of the work as a whole, and have given their approval for this version to be published.

Authorship Contributions. SD is the guarantor of the work and, as such, takes responsibility for the integrity of the manuscript content. SD and DK provided input at the conception of this narrative review, their opinions and recommendations based on their clinical experience throughout the drafting process. Both authors critically revised the article during the drafting process and approved of the final version to be published.
Disclosures. Sherwin C. D'Souza has participated as a speaker for AstraZeneca, BL-Lilly, Dexcom, and Novo Nordisk A/S and received consultancy fees from Novo Nordisk A/S. Davida F. Kruger has participated on advisory boards for Novo Nordisk, Abbott, Eli Lilly and Company, Sanofi Aventis, Janssen, Dexcom, Intarcia, and Merck; participated in speakers' bureaus for Janssen, Valeritas, AstraZeneca, BLLilly, Novo Nordisk, Dexcom, Lilly, Abbott, and Insulet; holds stocks or shares in Dexcom; and the Henry Ford Health System has received grants and/or research support from Novo Nordisk, the Helmsley Charitable Trust, Dexcom, Lexicon, and Abbott.

Compliance with Ethics Guidelines. This article is based on previously conducted studies and does not contain any studies with human participants or animals performed by any of the authors.

Data Availability. Data sharing not applicable to this article, as no datasets were generated or analyzed during the current study.

Open Access. This article is licensed under a Creative Commons Attribution-NonCommercial 4.0 International License, which permits any non-commercial use, sharing, adaptation, distribution and reproduction in any medium or format, as long as you give appropriate credit to the original author(s) and the source, provide a link to the Creative Commons licence, and indicate if changes were made. The images or other third party material in this article are included in the article's Creative Commons licence, unless indicated otherwise in a credit line to the material. If material is not included in the article's Creative Commons licence and your intended use is not permitted by statutory regulation or exceeds the permitted use, you will need to obtain permission directly from the copyright holder. To view a copy of this licence, visit http://creativecommons.org/licenses/by$\mathrm{nc} / 4.0 /$. 


\section{REFERENCES}

1. Davis CS, Fleming JW, Malinowski SS, Brown MA, Fleming LW. Ultra-long-acting insulins: a review of efficacy, safety, and implications for practice. J Am Assoc Nurse Pract. 2018;30:373-80.

2. Zinman B. Newer insulin analogs: advances in basal insulin replacement. Diabetes Obes Metab. 2013;15(Suppl 1):6-10.

3. International Diabetes Federation. IDF diabetes atlas. 9th edn, 2019.

4. Hirsch IB, Draznin B. Transition of patients to and from insulin degludec: A clinical challenge. J Clin Endocrinol Metab. 2020:dgz280.

5. Novo Nordisk A/S. Tresiba ${ }^{\circledR}$ prescribing information 2019. https://www.accessdata.fda.gov/ drugsatfda_docs/label/2019/203314s015s016lbl. pdf. Accessed Aug 2020.

6. Sanofi. Toujeo ${ }^{\circledR}$ prescribing information. 2019. https://www.accessdata.fda.gov/drugsatfda_docs/ label/2019/206538s012lbl.pdf. Accessed Augg 2020.

7. Becker RH, Dahmen R, Bergmann K, Lehmann A, Jax T, Heise T. New insulin glargine 300 units. $\mathrm{mL}^{-1}$ provides a more even activity profile and prolonged glycemic control at steady state compared with insulin glargine 100 units. $\mathrm{mL}^{-1}$ Diabetes Care. 2015;38:637-43.

8. Heise T, Kaplan K, Haahr HL. Day-to-day and within-day variability in glucose-lowering effect between insulin degludec and insulin glargine (100 $\mathrm{U} / \mathrm{mL}$ and $300 \mathrm{U} / \mathrm{mL}$ ): a comparison across studies. J Diabetes Sci Technol. 2018;12:356-63.

9. Goldman J, White JR. New insulin glargine 300 $\mathrm{U} / \mathrm{mL}$ for the treatment of type 1 and type 2 diabetes mellitus. Ann Pharmacother. 2015;49: 1153-61.

10. Ratner RE, Gough SC, Mathieu C, et al. Hypoglycaemia risk with insulin degludec compared with insulin glargine in type 2 and type 1 diabetes: a preplanned meta-analysis of phase 3 trials. Diabetes Obes Metab. 2013;15:175-84.

11. Wysham C, Bhargava A, Chaykin L, et al. Effect of insulin degludec vs insulin glargine U100 on hypoglycemia in patients with type 2 diabetes: the SWITCH 2 randomized clinical trial. JAMA. 2017;318:45-56.

12. Tibaldi JM. Evolution of insulin: from human to analog. Am J Med. 2014;127:S25-38.
13. Malcolm J, Halperin I, Miller DB, et al. In-hospital management of diabetes. Can J Diabetes. 2018;42(Suppl 1):S115-S12323.

14. American Diabetes Association. 15. Diabetes Care in the Hospital: Standards of Medical Care in Diabetes-2020. Diabetes Care. 2020;43:S193-S202.

15. Moghissi ES, Korytkowski MT, DiNardo M, et al. American Association of clinical endocrinologists and American diabetes association consensus statement on inpatient glycemic control. Diabetes Care. 2009;32:1119-31.

16. Egi M, Bellomo R, Stachowski E, et al. The interaction of chronic and acute glycemia with mortality in critically ill patients with diabetes. Crit Care Med. 2011;39:105-11.

17. Yong PH, Weinberg L, Torkamani N, et al. The presence of diabetes and higher $\mathrm{HBA}_{1 \mathrm{c}}$ are independently associated with adverse outcomes after surgery. Diabetes Care. 2018;41:1172-9.

18. Marik PE, Egi M. Treatment thresholds for hyperglycemia in critically ill patients with and without diabetes. Intensive Care Med. 2014;40:1049-51.

19. Kang ZQ, Huo JL, Zhai XJ. Effects of perioperative tight glycemic control on postoperative outcomes: a meta-analysis. Endocr Connect. 2018;7: R316-R327327.

20. Umpierrez GE, Smiley D, Jacobs S, et al. Randomized study of basal-bolus insulin therapy in the inpatient management of patients with type 2 diabetes undergoing general surgery (RABBIT 2 surgery). Diabetes Care. 2011;34:256-61.

21. Umpierrez GE, Smiley D, Zisman A, et al. Randomized study of basal-bolus insulin therapy in the inpatient management of patients with type 2 diabetes (RABBIT 2 trial). Diabetes Care. 2007;30: 2181-6.

22. Umpierrez GE, Hor T, Smiley D, et al. Comparison of inpatient insulin regimens with detemir plus aspart versus neutral protamine hagedorn plus regular in medical patients with type 2 diabetes. J Clin Endocrinol Metab. 2009;94:564-9.

23. Turchin A, Matheny ME, Shubina M, Scanlon JV, Greenwood B, Pendergrass ML. Hypoglycemia and clinical outcomes in patients with diabetes hospitalized in the general ward. Diabetes Care. 2009;32: 1153-7.

24. Curkendall SM, Natoli JL, Alexander CM, Nathanson BH, Haidar T, Dubois RW. Economic and clinical impact of inpatient diabetic hypoglycemia. Endocr Pract. 2009;15:302-12. 
25. Krinsley JS, Egi M, Kiss A, et al. Diabetic status and the relation of the three domains of glycemic control to mortality in critically ill patients: an international multicenter cohort study. Crit Care. 2013;17:R37.

26. Takeishi S, Mori A, Hachiya H, et al. Hypoglycemia and glycemic variability are associated with mortality in non-intensive care unit hospitalized infectious disease patients with diabetes mellitus. J Diabetes Investig. 2016;7:429-35.

27. Krinsley JS, Schultz MJ, Spronk PE, et al. Mild hypoglycemia is independently associated with increased mortality in the critically ill. Crit Care. 2011;15:R173.

28. Egi M, Bellomo R, Stachowski E, et al. Hypoglycemia and outcome in critically ill patients. Mayo Clin Proc. 2010;85:217-24.

29. Perez A, Ramos A, Carreras G. Insulin therapy in hospitalized patients. Am J Ther. 2020;27: e71-e7878.

30. Jonassen I, Havelund S, Hoeg-Jensen T, Steensgaard DB, Wahlund PO, Ribel U. Design of the novel protraction mechanism of insulin degludec, an ultra-long-acting basal insulin. Pharm Res. 2012;29: 2104-14.

31. Heise T, Nosek L, Bottcher SG, Hastrup H, Haahr H. Ultra-long-acting insulin degludec has a flat and stable glucose-lowering effect in type 2 diabetes. Diabetes Obes Metab. 2012;14:944-50.

32. Heise $\mathrm{T}$, Meneghini LF. Insulin stacking versus therapeutic accumulation: understanding the differences. Endocr Pract. 2014;20:75-83.

33. Kupcova V, Arold G, Roepstorff C, Hojbjerre M, Klim S, Haahr H. Insulin degludec: Pharmacokinetic properties in subjects with hepatic impairment. Clin Drug Investig. 2014;34:127-33.

34. Kiss I, Arold G, Roepstorff C, Bottcher SG, Klim S, Haahr H. Insulin degludec: pharmacokinetics in patients with renal impairment. Clin Pharmacokinet. 2014;53:175-83.

35. Biester $\mathrm{T}$, Blaesig $\mathrm{S}$, Remus $\mathrm{K}$, et al. Insulin degludec's ultra-long pharmacokinetic properties observed in adults are retained in children and adolescents with type 1 diabetes. Pediatr Diabetes. 2014;15:27-33.

36. Korsatko S, Deller S, Mader JK, et al. Ultra-long pharmacokinetic properties of insulin degludec are comparable in elderly subjects and younger adults with type 1 diabetes mellitus. Drugs Aging. 2014;31:47-53.
37. Marso SP, McGuire DK, Zinman B, et al. Efficacy and safety of degludec versus glargine in type 2 diabetes. N Engl J Med. 2017;377:723-32.

38. Korsatko S, Deller S, Koehler G, et al. A comparison of the steady-state pharmacokinetic and pharmacodynamic profiles of 100 and $200 \mathrm{U} / \mathrm{mL}$ formulations of ultra-long-acting insulin degludec. Clin Drug Investig. 2013;33:515-21.

39. Steinstraesser A, Schmidt R, Bergmann K, Dahmen $\mathrm{R}$, Becker RH. Investigational new insulin glargine $300 \mathrm{U} / \mathrm{mL}$ has the same metabolism as insulin glargine 100 U/mL. Diabetes Obes Metab. 2014;16: 873-6.

40. Cheng AYY, Patel DK, Reid TS, Wyne K. Differentiating basal insulin preparations: Understanding how they work explains why they are different. Adv Ther. 2019;36:1018-30.

41. Gerstein HC, Bosch J, Dagenais GR, et al. Basal insulin and cardiovascular and other outcomes in dysglycemia. N Engl J Med. 2012;367:319-28.

42. Philis-Tsimikas A, Klonoff DC, Khunti K, et al. Risk of hypoglycaemia with insulin degludec versus insulin glargine U300 in insulin-treated patients with type 2 diabetes: the randomised, head-to-head CONCLUDE trial. Diabetologia. 2020;63:698-710.

43. Kawaguchi Y, Sawa J, Sakuma N, Kumeda Y. Efficacy and safety of insulin glargine $300 \mathrm{U} / \mathrm{mL}$ vs insulin degludec in patients with type 2 diabetes: a randomized, open-label, cross-over study using continuous glucose monitoring profiles. J Diabetes Investig. 2019;10:343-51.

44. Rosenstock J, Cheng A, Ritzel R, et al. More similarities than differences testing insulin glargine 300 Units/mL versus insulin degludec 100 Units/mL in insulin-naive type 2 diabetes: The randomized head-to-head BRIGHT trial. Diabetes Care. 2018;41: 2147-54.

45. Tibaldi J, Hadley-Brown M, Liebl A, et al. A comparative effectiveness study of degludec and insulin glargine $300 \mathrm{U} / \mathrm{mL}$ in insulin-naive patients with type 2 diabetes. Diabetes Obes Metab. 2019;21: 1001-9.

46. Del Prato S. How conclusive is the CONCLUDE trial? Diabetologia. 2020;63:692-7.

47. Riddle MC, Bolli GB, Home PD, et al. Efficacy and safety of flexible versus fixed dosing intervals of insulin glargine $300 \mathrm{U} / \mathrm{mL}$ in people with type 2 diabetes. Diabetes Technol Ther. 2016;18:252-7.

48. Prescrire Editorial Staff. Insulin use: Preventable errors. Prescrire Int. 2014;23:14-7. 
49. Umpierrez G. A trial comparing insulin degludec and glargine U100 for management of hospitalized and discharged patients with type 2 diabetes. 2018. https://clinicaltrials.gov/ct2/show/NCT03336528. Accessed Aug 2020.

50. Suzuki J, Yamakawa T, Oba M, et al. Efficacy and safety of insulin degludec U100 and insulin glargine U100 in combination with meal-time bolus insulin in hospitalized patients with type 2 diabetes: an open-label, randomized controlled study. Endocr J. 2019;66:971-82.

51. Takeishi S, Mori A, Fushimi N, et al. Evaluation of safety of insulin degludec on undergoing total colonoscopy using continuous glucose monitoring. J Diabetes Investig. 2016;7:374-80.

52. Fatati G, Di Donato A, Grandone I, et al. Impact of insulin degludec in hospitalized patients with and without type 2 diabetes requiring parenteral/enteral nutrition: an observational study. Adv Ther. 2018;35:809-16.

53. Simioni N, Filippi A, Scardapane M, Nicolucci A, Rossi MC, Frison V. Efficacy and safety of insulin degludec for hyperglycemia management in noncritical hospitalized patients with diabetes: an observational study. Diabetes Ther. 2017;8:941-6.

54. Pasquel FJ, Lansang MC, Khowaja A, et al. A randomized controlled trial comparing glargine U300 and glargine $\mathrm{U} 100$ for the inpatient management of medicine and surgery patients with type 2 diabetes: Glargine u300 hospital trial. Diabetes Care. 2020. https://doi.org/10.2337/dc19-1940.

55. Umpierrez GE, Reyes D, Smiley D, et al. Hospital discharge algorithm based on admission HbA1c for the management of patients with type 2 diabetes. Diabetes Care. 2014;37:2934-9.

56. Zhu L, She ZG, Cheng X, et al. Association of blood glucose control and outcomes in patients with COVID-19 and pre-existing type 2 diabetes. Cell Metab. 2020;31(1068-77):e3.

57. Wu L, Girgis CM, Cheung NW. COVID-19 and Diabetes: insulin requirements parallel illness severity in critically unwell patients. Clin Endocrinol (Oxf). 2020

58. Apicella M, Campopiano MC, Mantuano M, Mazoni L, Coppelli A, Del Prato S. COVID-19 in people with diabetes: understanding the reasons for worse outcomes. Lancet Diabetes Endocrinol. 2020. https://doi.org/10.1111/cen.14288.

59. Silva-Perez LJ, Benitez-Lopez MA, Varon J, Surani S. Management of critically ill patients with diabetes. World J Diabetes. 2017;8:89-96.
60. Umpierrez GE, Hellman R, Korytkowski MT, et al. Management of hyperglycemia in hospitalized patients in non-critical care setting: an endocrine society clinical practice guideline. J Clin Endocrinol Metab. 2012;97:16-38.

61. Corsino L, Dhatariya K, Umpierrez G. Management of diabetes and hyperglycemia in hospitalized patients. In: Feingold KR, Anawalt B, Boyce A, et al., eds. Endotext. South Dartmouth (MA): MDText.com, Inc., 2000

62. Hulkower RD, Pollack RM, Zonszein J. Understanding hypoglycemia in hospitalized patients. Diabetes Manag (Lond). 2014;4:165-76.

63. Heise T, Korsatko S, Nosek L, et al. Steady state is reached within 2-3 days of once-daily administration of degludec, a basal insulin with an ultralong duration of action. J Diabetes. 2016;8:132-8.

64. Shiramoto $M$, Eto $T$, Irie $S$, et al. Single-dose new insulin glargine $300 \mathrm{U} / \mathrm{mL}$ provides prolonged, stable glycaemic control in Japanese and European people with type 1 diabetes. Diabetes Obes Metab. 2015;17:254-60.

65. Anderson SL, Trujillo JM, Anderson JE, Tanenberg RJ. Switching basal insulins in type 2 diabetes: Practical recommendations for health care providers. Postgrad Med. 2018;130:229-38.

66. Heise T, Pieber TR. Towards peakless, reproducible and long-acting insulins. An assessment of the basal analogues based on isoglycaemic clamp studies. Diabetes Obes Metab. 2007;9:648-59.

67. Novo Nordisk A/S. Levemir ${ }^{\circledR}$ dosing and administration. 2019. https://www.levemirpro.com/dosingand-administration.html. Accessed Aug 2020.

68. Novo Nordisk A/S. Levemir ${ }^{\circledR}$ prescribing information 2020. https://www.novo-pi.com/levemir.pdf. Accessed Aug 2020.

69. Sanofi. Lantus ${ }^{\circledR}$ prescribing information. 2019. https://www.accessdata.fda.gov/drugsatfda_docs/ label/2019/021081s073s074lbl.pdf. Accessed Aug 2020 .

70. Lucidi P, Porcellati F, Marinelli Andreoli A, et al. Pharmacokinetics and pharmacodynamics of NPH insulin in type 1 diabetes: The importance of appropriate resuspension before subcutaneous injection. Diabetes Care. 2015;38:2204-10.

71. Eli Lilly and Company. Humulin ${ }^{\circledR} \mathrm{N}$ prescribing information. 2019. https://uspl.lilly.com/ humulinn/humulinn.html\#ppi. Accessed Feb 2019.

72. Petznick A. Insulin management of type 2 diabetes mellitus. Am Fam Physician. 2011;84:183-90. 